\title{
RELAÇÕES DE GÊNERO EM CATÁLOGOS DE BRINQUEDOS: (CONTRA)INDICAÇÕES PARA O BRINCAR*
}

\author{
Fernanda Battagli Kropeniscki ${ }^{1}$ \\ Fátima Cristina Vieira Perurena ${ }^{1}$
}

\begin{abstract}
RESUMO: Este artigo buscou discutir as relaçóes de gênero retratadas nos catálogos de brinquedos de uma Empresa X, localizada na Região Sul do Brasil, no período de 2009 a 2015. A partir de uma análise das imagens apresentadas nos catálogos, foram constatadas mudanças e permanências na produção e oferta de brinquedos. Inicialmente direcionados para meninas ou meninos, os brinquedos ofertados demarcavam limites para o feminino e para o masculino. Quando todos os brinquedos passaram a ser indicados para elas e para eles, um binarismo camuflado foi mantido e a problemática das cores entrou em cena. Diante desse cenário, considera-se que, em meio às transformaçóes já ocorridas nas relaçóes de gênero, a produção e a oferta de brinquedos também vêm se modificando, porém, a passos lentos.
\end{abstract}

Palavras-chave: Brinquedos. Relaçóes de gênero. Crianças.

\section{GENDER RELATIONS IN TOYS CATALOGS: (CONTRA)INDICATIONS TO PLAY}

\begin{abstract}
This paper aimed to discuss gender relations portrayed in toy catalogs of Company X, located in southern Brazil, from 2009 to 2015. As from an analysis of the images presented in catalogs, changes and continuities in the production and supply of toys were found. Initially targeted to girls or boys, the offered toys demarcated boundaries for the feminine and the masculine. When all the toys began to be indicated for girls and for boys, a camouflaged binarism was maintained and problems of color appeared. In this scenario, it is considered that, amid the changes that have already occurred in gender relations, production and supply of toys are also changing, but at a slow pace.
\end{abstract}

Keywords: Toys. Gender relations. Children.

\footnotetext{
*Este artigo é resultante do projeto de pesquisa do Mestrado em Ciências Sociais da UFSM, defendido em agosto de 2015, intitulado "Retratos de relaçôes de gênero em catálogos de brinquedos", apoiado pela CAPES.

${ }^{1}$ Universidade Federal de Santa Maria - Santa Maria (RS), Brasil. E-mail: nandabk_fer@hotmail.com DOI: 10.1590/ES0101-73302017155576
} 


\title{
LES RELATIONS DE GENRE DANS LES CATALOGUES DE JOUETS: (CONTRE)-INDICATIONS À JOUER
}

\begin{abstract}
RESUME: Cet article vise à discuter les relations de genre représentées dans les catalogues de jouets de la société $\mathrm{X}$, qui est situé dans le sud du Brésil, pendant la période de 2009-2015. A partir d'une analyse des images présentées dans les catalogues, des changements et des continuités ont été remarqués dans la production et la distribution de jouets. Initialement ciblés pour les filles ou pour les garçons, les jouets proposés délimitaient le féminin et le masculin. Lorsque tous les jouets ont commencé à être distribués aux filles comme aux garçons, une dualité camouflée a été maintenue et la problématique des couleurs est entrée en jeu. Dans ce scénario, il est considéré que, parmi les changements qui ont déjà eu lieu dans les rapports entre les sexes, la production et la distribution de jouets est également en train de se transformer, mais à un rythme plus lent.
\end{abstract}

Mots-clés: Jouets. Les relations de genre. Enfants.

\section{Introdução}

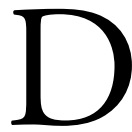

e todas as fases da vida, a infância é um dos momentos mais deslumbrantes. É quando a imaginação invade as brincadeiras, e cada criança pode criar realidades e fazer de conta que o mundo é como imagina. Contudo, não podemos fazer de conta que essa dimensão infantil nada carrega do mundo real. Ao contrário, muitas vezes ela é planejada para suprir necessidades de um mundo que já perdeu seu encanto.

Quando direcionamos o olhar para esse momento da vida, nós nos deparamos com inúmeros mecanismos que perpassam a formação das crianças, dentre os quais se encontram os brinquedos. Objetos que dáo suporte às brincadeiras, apresentando variaçóes incontáveis; objetos que se transformam ora nisso, outrora naquilo, que carregam marcas de tempos e espaços diversos. Os brinquedos são um dos meios pelos quais as crianças interagem com a cultura e dela se apropriam.

Os brinquedos industrializados podem dispersar a imaginação de quem brinca, pois já sugerem histórias e indicam o caminho da brincadeira. A imaginação não precisa ser intensa, o cenário está pronto, materializado, suas formas se conformam com uma realidade selecionada, seu colorido traz tonalidades que provocam sensaçóes, que carregam intençóes. Ao serem fabricados, esses brinquedos retratam não apenas um objeto material, mas também revelam o olhar dos fabricantes sobre as crianças e suas relaçóes no mundo. As diversas mensagens comunicadas pelos brinquedos nem sempre podem ser percebidas quando não levamos em consideração alguns traços da cultura na qual esses brinquedos estão inseridos. 
A partir de um olhar atento aos catálogos de brinquedos de uma determinada fábrica, foi possível perceber uma distinção na oferta de brinquedos para meninas e para meninos. Devemos considerar que nos encontramos em uma sociedade marcada por binarismos, de modo que as relaçôes de gênero não fogem a essa regra, e são configuradas a partir de uma oposição entre feminino e masculino. Os brinquedos industrializados, ao retratarem realidades selecionadas, buscam se conformar às padronizaçóes culturais, de maneira a atrair seu público consumidor. Com isso, feminilidades e masculinidades são representadas em catálogos de brinquedos, os quais buscam direcionar o brincar de meninas e meninos. Mas o que se esconde nesse direcionamento? Como se configura o brincar de meninas e meninos proposto em catálogos de brinquedos?

O presente artigo coloca em discussão as relaçóes de gênero retratadas nos catálogos de brinquedos de uma Empresa X, localizada na Região Sul do país, no período de 2009 a 2015, a partir de uma análise das transformaçóes ocorridas na oferta de brinquedos ao longo desses anos.

Após entrar em contato com o setor de marketing da Empresa X, tivemos acesso aos catálogos e identificamos uma seçâo de "Jogos e Brinquedos", que se mantinha anualmente desde a criação do setor de marketing da empresa, em 1998. Contudo, desde sua fundação, em 1947, a empresa teve como foco a produção de materiais escolares e pedagógicos, produzidos em madeira. O plástico passou a ser usado na fabricação dos brinquedos a partir de 1990. Até o ano 2008 os catálogos não apresentavam uma consistência de brinquedos relevante para a pesquisa a ser realizada. Justifica-se, entáo, o período abordado pela maior variedade de linhas/coleçóes de brinquedos ofertadas a partir de 2009, cada qual carregando cores e temáticas relevantes para a discussão proposta.

As imagens de brinquedos encontradas nos catálogos em questão foram analisadas a partir de uma aproximaçáo com a semiologia dos discursos sociais, discutida por Inesita Araújo (2000), bem como com a análise semiótica de imagens paradas, abordada por Gemma Penn (2002). Para Araújo (2000, p. 120), semiologia é a "ciência que estuda os fenômenos sociais como fenômenos de produçáo de sentido". Desse modo, a autora chama atenção para os discursos sociais como produtores de sentidos, os quais não estão prontos em cada discurso, mas são produzidos em meio a relaçóes sociais e contextos institucionais que modelam os sentidos. A presente pesquisa, por não trabalhar com o conceito de discursos sociais, desloca a contribuição de Araújo (2000) para as imagens de brinquedos apresentadas em catálogos, as quais também produzem sentidos de acordo com o contexto no qual se inserem.

A partir desse deslocamento proposto, colocamos em cena as contribuiçóes de Penn (2002, p. 324), que considera o ato de ler um texto ou uma imagem como um processo interpretativo, no qual "o sentido é gerado na interaçáo do leitor com o material". Ao diferenciar linguagem e imagem, a autora aponta esta como polissêmica ou ambígua, chamando atençáo para a necessidade de desvendar conhecimentos culturais para que a imagem possa ser lida e compreendida em um deter- 
minado contexto. Desse modo, a leitura das imagens dos brinquedos que se apresentam nos catálogos ocorre com a busca de traços culturais que nelas se inscrevem.

O propósito de toda essa análise esteve em traçar um histórico das relaçóes de gênero apresentadas na produção e oferta de brinquedos da Empresa X, ao longo dos últimos sete anos. Nesse percurso, buscou-se observar as transformaçóes ocorridas, colocar em discussão as relações de gênero que caracterizam nosso contexto social, bem como problematizar a construção do feminino e do masculino.

Antes de adentrarmos os catálogos, faz-se necessário compreender a que(m) estamos nos referindo com toda essa discussão. Temos aqui um cenário composto por brinquedos e crianças brincantes. Mas o que entendemos por "crianças"? Meninas e meninos também são crianças? E os brinquedos, por que tanta importância dispendida a eles? Por que questionar a oferta desses objetos, que apenas auxiliam as brincadeiras?

Ao percorrer os catálogos, deparamo-nos com retratos de relações de gênero - como se fossem um álbum de fotos. A cada ano, mudanças são anunciadas, mas a tradição é mantida. A realidade que se apresenta nos brinquedos ofertados é selecionada, assim como o foco de uma fotografia. Aquilo que não atrai sai de cena, fica apagado. Mas quem está por trás dessas lentes seletivas? A quem interessa a produção e oferta de brinquedos?

\section{Sobre brinquedos e crianças brincantes}

Ao voltarmos nossa atenção para a produção e oferta de brinquedos, não é exatamente com os brinquedos que estamos preocupadas, mas com as relaçóes estabelecidas com o público a quem se dirigem esses brinquedos. Pessoas que compram, vendem, presenteiam e, principalmente, crianças que brincam. O que vem sendo produzido e ofertado para dar suporte às brincadeiras das crianças? Como o brincar de meninas e meninos é encarado por fabricantes de brinquedos? Esses questionamentos nos convidam a refletir sobre a formação diferenciada de meninas e meninos, que perpassa também o brincar.

Para início de conversa, devemos nos situar em meio a tantas conceituaçôes que podem existir nesse campo. Crianças sempre existiram, mas os olhares a elas direcionados se modificaram no decorrer da história. Para Philippe Ariès (1986, p. 65): "A descoberta da infância começou sem dúvida no século XIII, e sua evolução pode ser acompanhada na história da arte e na iconografia dos séculos XV e XVI". Mas, segundo o autor, é o século XVII que se apresenta como um importante marco na evoluçáo dos temas relativos à infância. Atualmente, quando nos referimos a crianças, diversas ideias preenchem nossos pensamentos. Seriam elas seres humanos incompletos? Adultos em miniatura? Uma tábula rasa? Um vir-a-ser? Seres dotados de fantasias? Enfim, muitos foram e ainda são os 
olhares lançados às crianças ao longo do tempo, cada um contornando diferentes imagens para definir o que elas são. Ainda hoje não temos uma definição emoldurada, que contemple todas as reflexóes sobre o assunto.

Desse modo, considerando que as noções de criança e de infância são construções históricas e sociais, partimos do entendimento de crianças conforme o pensamento de Clarice Cohn (2005, p. 35), ou seja, não como seres incompletos, conformados pela cultura, mas como seres que também participam da produçáo de cultura, que "elaboram sentidos para o mundo e suas experiências". No entanto, ao longo da vida, somos treinadas/treinados para reproduzir, e nossa capacidade de criar vai, aos poucos, atrofiando. Nesse trajeto, sem pedir licença, apenas direcionamos a formação de meninas e meninos, sem muitas vezes dar espaço para a produçáo cultural das crianças, que passa despercebida, como se não fosse digna de reconhecimento.

Antes mesmo de uma criança nascer, quando se descobre o sexo do bebê, tudo toma um rumo. Meninas e meninos, futuras mulheres e homens, passam a ser idealizadas/idealizados, modeladas/modelados, conforme os padrōes culturais de gênero. É preciso considerar que, apesar de tomarem como base o sexo biológico, as construções de gênero não se resumem a ele. De acordo com Heleieth Saffioti (1992, p. 187):

As relaçóes de gênero não resultam da existência de dois sexos, macho e fêmea. [...] O vetor direciona-se, ao contrário, do social para os indivíduos que nascem. Tais indivíduos são transformados, através das relaçóes de gênero, em homens ou mulheres, cada uma destas categorias-identidades excluindo a outra.

Saffioti (1992) chama atenção para a existência de uma teia de relações sociais, na qual se entrelaçam três grandes subestruturas - classe, etnia e gênero, responsáveis por moldar a sociedade. Nesse entendimento, as relaçóes sociais são responsáveis por moldar continuamente as construçóes de gênero, bem como de classe e etnia, as quais se encontram interligadas. A estrutura social que se apresenta é apenas uma possibilidade de organização que resulta das relaçôes sociais. Desse modo, masculino e feminino não devem ser tidos como blocos fechados, mas como construçôes sociais que sofrem modificaçôes em diferentes contextos.

No entanto, apesar da existência de feminilidades e masculinidades, permeadas tanto por construçóes femininas, quanto masculinas, diversos espaços de socialização se mantêm estruturados de maneira a reafirmar uma oposição e complementaridade entre masculino e feminino. Possibilidades distintas se abrem para elas e para eles, e outras se fecham. Nesse contexto binário, desigualdades de gênero são conservadas. Quando crianças, meninas e meninos aprendem que, embora sejam crianças, são diferentes umas das outras, e aprendem também que o mundo é pensado de maneira diferente para eles e para elas, por eles e por elas. Essas diferenças dificilmente são explicadas. Mas será que existe explicação? 
Nesse processo de formação, um dos momentos mais criativos da vida, o momento de brincar, pode ser rasgado por segundas e terceiras intençóes. Segundo Donald Woods Winnicott (1975), a brincadeira está localizada em uma área da experiência, em que se contrastam a realidade pessoal e o mundo real que pode ser percebido pelo indivíduo. Para Winnicott (1975, p. 172), é no brincar criativo que se desenvolve "o uso de símbolos que representam, a um só e mesmo tempo, os fenômenos do mundo externo e os fenômenos da pessoa individual". No entanto, a brincadeira muitas vezes é vista como um momento oportuno para a preparação das crianças para a vida adulta. Desse modo, a preocupação com o futuro acaba privando as crianças de seu tempo de brincar, de sua capacidade de agir no mundo, de criar, de sentir. As brincadeiras são direcionadas, a criança adormece, passa a ser treinada. Para Gilmar Staviski e Elenor Kunz (2015, p. 60):

Uma visão que entende a brincadeira somente pela ótica do adulto e que se preocupa exclusivamente com os supostos benefícios gerados por ela, ou seja, os aspectos funcionalistas, não reconhece os desejos e subjetividades presentes no sujeito principal desta relação enquanto brinca - a criança.

Nesse processo de formação para a vida adulta, fazem-se visíveis as distinções de gênero encontradas em muitas brincadeiras. Meninas geralmente são treinadas para serem mães e donas de casa, enquanto meninos se preparam para um futuro mais liberto e aparentemente mais autônomo, porém igualmente direcionado.

Diferentemente do jogo, o brinquedo não é marcado por uma função precisa. Como aponta Gilles Brougère (2010, p. 13), "trata-se, antes de tudo, de um objeto que a criança manipula livremente, sem estar condicionado às regras ou a princípios de utilização de outra natureza”. Para o autor, no brinquedo o valor simbólico se sobrepóe à função do objeto. A brincadeira pode ser entendida como função do brinquedo, no entanto, ela mesma "escapa a qualquer função precisa e é, sem dúvida, esse fato que a definiu, tradicionalmente, em torno das ideias de gratuidade e até de futilidade" (BROUGÈRE, 2010, p. 14).

Para Paulo de Salles Oliveira (1989), a importância do brinquedo reside justamente em sua não seriedade, o que lhe confere a capacidade de instigar a imaginação das crianças. Ao considerar o simbólico como a própria função do objeto, Brougère (2010, p. 15) aponta que "o objeto deve significar, deve traduzir um universo real ou imaginário que será a fonte da brincadeira”. No mesmo sentido, Tizuko Morchida Kishimoto (2011, p. 24) aponta que o brinquedo, como objeto, "é sempre suporte de brincadeira. É o estimulante material para fazer fluir o imaginário infantil”. No entanto, a imaginação provocada pelos brinquedos é, muitas vezes, desviada. Nesse ponto, Walter Benjamin (2002, p. 93) chama atenção para o fato de que, "quanto mais atraentes, no sentido corrente, são os brinquedos, mais se distanciam dos instrumentos de brincar; quanto mais ilimitadamente a imitação se manifesta neles, tanto mais se desviam da brincadeira viva”. 
Segundo Maria Sílvia da Rocha (2005), em um jogo de faz de conta os objetos, os papéis representados e as temáticas envolvidas partem da experiência da criança em sua realidade sociocultural, no entanto, ao fazer de conta, elas podem subverter possibilidades concretas de ação, criar novos enredos e personagens para suas histórias.

Ao caírem como cometas nos cenários das brincadeiras, muitos brinquedos podem destruir tudo o que havia sido criado. Com formas e cores sugestivas, os brinquedos industrializados podem se transformar em barreiras para a imaginação. Barreiras que também separam o feminino do masculino. Produzidos e ofertados para meninas ou meninos, muitos brinquedos refletem as relaçóes de gênero que caracterizam uma cultura, e ensinam às crianças diferentes posiçōes de mulheres e homens em uma estrutura social. Nas palavras de Edda Bomtempo (2011, p. 75), o "brinquedo aparece como um pedaço de cultura colocado ao alcance da criança. [...] A manipulação do brinquedo leva a criança à ação e à representação, a agir e a imaginar".

De acordo com Brougère (2010), os brinquedos contribuem para a socialização das crianças, pois constituem uma das formas de apropriação da cultura. $\mathrm{Na}$ mesma direção, Kishimoto (2011, p. 20) aponta que "o brinquedo estimula a representação, a expressão de imagens que evocam aspectos da realidade". Segundo a autora é possível afirmar que "um dos objetivos do brinquedo é dar à criança um substituto dos objetos reais, para que possa manipulá-lo" (KISHIMOTO, 2011, p. 21). Como representaçóes do mundo social, os brinquedos permitem às crianças vivenciarem situaçôes que remetem às práticas cotidianas, muitas delas carimbadas como femininas ou masculinas. Segundo Cláudia Vianna e Daniela Finco (2009, p. 272), "os brinquedos permitidos e disponibilizados para as crianças refletem os processos de feminilização e masculinização, onde as crianças aprendem de forma mascarada e prazerosa, a comportar-se como 'verdadeiros' meninos e meninas".

Contudo, nem sempre as crianças se conformam às padronizaçóes culturais, visto que, conforme apontado por Cohn (2005), as crianças não apenas incorporam a cultura, mas criam sentidos para o mundo à sua volta. Na mesma direção, Michel de Certeau (1998, p. 40), ao tratar das "artes de fazer" como uma prática de dissimulação, afirma que:

A presença e a circulação de uma representação [...] náo indicam de modo algum o que ela é para seus usuários. É ainda necessário analisar a sua manipulaçâoo pelos praticantes que não a fabricam. Só então é que se pode apreciar a diferença ou a semelhança entre a produção da imagem e a produção secundária que se esconde nos processos de sua utilização.

Em meio ao faz de conta, o brinquedo, ao ser manipulado pelas crianças, pode sofrer transformaçóes e ganhar outras significaçôes. Ao entrarem em cena, os brinquedos ganham vida, constituem inúmeros cenários e personagens 
em meio às brincadeiras. Contudo, o foco da presente pesquisa reside na produção e oferta de brinquedos, o que nos condiciona a permanecer, neste momento, pelos bastidores, não sendo possível, na posição em que nos encontramos, vislumbrar o que passa a ser encenado.

\section{Retratos de relações de gênero}

Ao adentrar os catálogos da Empresa X, muitos poderiam ser os olhares lançados a cada imagem de brinquedo ofertado, cada qual trazendo novas discussóes, o que significa que as análises aqui apresentadas não consolidam verdades, mas traduzem uma interpretação, em meio a tantas possíveis, acerca do objeto pesquisado. Desse modo, seguimos a discussáo traçando contornos que configuram nosso olhar sobre os catálogos em questão.

O primeiro catálogo analisado, referente ao ano 2009, é marcado por mudanças em relação aos anos anteriores, visto que apresenta maior variedade de brinquedos ofertados. Esses brinquedos encontram-se separados por linhas temáticas, umas ofertadas para meninas, outras para meninos. Nesse catálogo, encontramos o lançamento de duas linhas de brinquedos representantes do ambiente doméstico, ambas indicadas apenas para meninas, a partir de 3 anos de idade: a "Casinha Flor", com cores predominantemente lilás e branca; e a "Disney Princesas", combinando a cor branca com tons de rosa e roxo. Destacamos a linha "Casinha Flor", que se mantém em catálogo até 2015. Dentre os brinquedos ofertados, estavam: fogão, refrigeradores, micro-ondas, máquina para lavar louças e máquina para lavar roupas. Nesse mesmo ano, foram lançadas quatro linhas de brinquedos indicadas apenas para meninos, a partir de 3 anos de idade: "Pinball Eletrônico", "Carrinho CR" e "Carrinho F1", com temáticas de corridas de carro e predominância das cores vermelha, azul, amarela e preta; e "Comando X", com cores verde e marrom (camuflado), em oito diferentes cenários de guerra.

Nessa aproximação, ficou evidente um direcionamento proposto para o brincar de meninas e meninos, que segue em direçôes opostas. Segundo Brougère (2010, p. 69), o brinquedo proporciona às crianças o contato com um "discurso cultural sobre a sociedade" que, nesse caso, configura um modelo binário de gênero. Para elas estava reservado o ambiente doméstico, tingido com os tradicionais tons de rosa, que caracterizam um padrão de feminilidade no contexto em que nos encontramos. Em contrapartida, a velocidade das pistas e os perigos da guerra representavam situaçóes reservadas aos meninos.

O catálogo do ano seguinte é marcado pela presença massiva de blocos de encaixe, que permanece até 2015. As temáticas propostas pelas linhas dos blocos de encaixe, bem como o ambiente doméstico apresentado na linha "Casinha Flor”, configuram nosso foco de análise. Conforme o pensamento de Penn (2002), buscamos focar o caráter construído das imagens, com base na identificaçáo de 
elementos culturais que configuram a oferta de brinquedos, visto que a partir das marcas inscritas nas imagens podemos compreender os motivos que concebem aos brinquedos suas principais características. Desse modo, cores e situações representadas pelos brinquedos são pontos chave para essa análise.

Em 2010, foram lançadas 9 linhas de brinquedos, todas blocos de encaixe, indicadas apenas para meninos a partir de 6 anos de idade, totalizando 30 brinquedos, com variaçóes entre 30 e 713 peças. "Supercarro" (40 peças), "Corredores Furiosos" (30 peças), "Corrida Maluca" (entre 59 e 62 peças) e "Super Máquina” (97 peças) prometiam a velocidade nas estradas e disputas acirradas com carros de corrida. Cenários de polícia e bombeiros, variando de 119 a 713 peças, comportavam os "Defensores da Ordem", responsáveis por manter a ordem na cidade. Com a "Cidade em Obras", muito trabalho deveria ser dispendido para a construção de 'caçamba', 'escavadeira', 'betoneira' e 'caminhão', máquinas que variavam de 142 a 189 peças. "Super Robô", "Andróide" e "Robô Guerreiro" nos levavam a missóes espaciais, com robôs variando de 55 a 184 peças. A indicação de gênero que acompanhava cada brinquedo ofertado direcionava aventuras e responsabilidades a meninos, desconsiderando a presença feminina nos cenários sugeridos.

Em relação ao ambiente doméstico ofertado pela linha "Casinha Flor", o catálogo de 2010 trouxe algumas modificações na indicação de gênero dos brinquedos. Três modelos de refrigerador, um fogão, um micro-ondas, uma máquina de lavar louças e uma máquina de lavar roupas, já ofertados no catálogo anterior, passaram a ser indicados também para meninos. Em contrapartida, outros onze brinquedos foram lançados nessa mesma linha, com indicação apenas para meninas. $\mathrm{O}$ retrato apresentado, que se mantém nos catálogos de 2011 e 2012, configura contornos de uma divisão sexual do trabalho doméstico. Para Danièle Kergoat (2003, p. 4), "falar em termos de divisão sexual do trabalho é ir mais além de uma simples constatação de desigualdades: é articular esta descrição do real com uma reflexão sobre os processos pelos quais a sociedade utiliza esta diferenciação para hierarquizar estas atividades".

Em relação ao trabalho doméstico ofertado nos catálogos de 2010 a 2012, observamos que aos meninos foram indicados eletrodomésticos de grande porte, que geralmente facilitam o trabalho doméstico. Por outro lado, apenas meninas foram convidadas ao trabalho que demanda maior dedicaçáo e nem sempre recebe o devido valor. Pia (16 acessórios); Kit cozinha (16 peças); Berço (com porta coisas do bebê, musical); Banheira (som de água); Cafeteira ( 2 xícaras, 2 colheres, luz e som); Torradeira (som e luz); Espremedor de frutas ( 2 copos, 2 colheres e 2 pratos, gira de verdade); Liquidificador ( 2 copos e 2 colheres, gira de verdade); Batedeira (funçóes que funcionam de verdade, pazinhas intercambiáveis, parte superior móvel e que funciona em separado); Ferro de passar roupas (dispositivo para água que funciona de verdade, botão para luzinha); e Caixa registradora com balança (cheia de cores e sons, faz som quando se passa o cartão, tem leitor de código de barras iluminado e com som, uma esteira deslizante para as compras, uma 
gaveta com chave que abre sozinha, a calculadora com som de caixa registradora e a balança com mostrador que se movimenta de verdade): são 11 brinquedos que configuram cenas nas quais apenas as meninas assumem tarefas como lavar a louça na pia quando não se dispóe de lavadora de louças, passar a roupa que encontra-se amassada, preparar alimentos utilizando liquidificador, batedeira, torradeira, cafeteira e espremedor de frutas, além de realizar as compras de casa e cuidar de bebês.

Nesse cenário, é desconsiderada a presença masculina e se reafirma a maternação ${ }^{2}$ exclusiva de mulheres que, conforme colocado por Nancy Chodorow (1990, p. 226), é responsável por preparar "os homens para a participação na família e sociedade machista, para sua participação menos emocional na vida familiar, e para sua participação no mundo capitalista do trabalho". Com isso, a oferta desses brinquedos propóe aos meninos uma pequena parcela do trabalho doméstico, na qual eles são convidados apenas a auxiliar, sem tomar para si as responsabilidades inerentes a esse ambiente, que ficam a cargo das meninas.

A inserção de mulheres no mercado de trabalho não significou a substituição do trabalho doméstico, ao contrário, resultou em um acúmulo de tarefas. Conforme apontado por Maria Cristina Aranha Bruschini (2007, p. 571), "as condiçôes de desigualdade perante os homens se revelam também na persistência da responsabilidade das mulheres e das mães pelos afazeres domésticos e pelos cuidados com as crianças e demais familiares". Nesse sentido, Helena Hirata e Danièle Kergoat (2007, p. 602) chamam atençáo para o fato de que, apesar de uma "reorganização simultânea do trabalho no campo assalariado e no campo doméstico", a conciliação de vida familiar e vida doméstica cabe quase que exclusivamente às mulheres e, se essa conciliação não ocorre, o trabalho doméstico é externalizado e fica a cargo, geralmente, de outras mulheres.

Como já foi colocado, esse direcionamento de tarefas apresentado pela linha "Casinha Flor" foi mantido até 2012. Nesse período, outros lançamentos de blocos de encaixe foram ofertados a meninos, a partir de 6 anos de idade. No catálogo de 2011, foram lançadas 2 linhas de blocos de encaixe: "Embarque Imediato", composta por 2 cenários - Avião de Passageiros (434 peças) e Aeroporto (791 peças), com cores predominantemente branca, azul e cinza —; e "Mecânicos em Ação", apresentando 1 oficina mecânica de carros, com 520 peças, combinando as cores branca, verde, amarela e cinza. Além dessas 2 linhas, outros brinquedos foram acrescentados às linhas já existentes, totalizando, em 2011, 38 conjuntos de blocos de encaixe.

Seguindo o percurso, no catálogo de 2012 foram lançadas quatro linhas de blocos de encaixe. Para ampliar o setor de transportes, foram inaugurados o "Porto Internacional", composto de 2 cenários, de 289 e 801 peças, nas cores azul, branca, cinza, vermelha e verde, e o "Trem Expresso", com 2 cenários coloridos principalmente de vermelho, preto e cinza, um com 320 peças e outro com 721 . A defesa de territórios ficou por conta da "Aliança Justiça e Paz", cujos cenários propostos variavam entre 226 e 577 peças, com cores predominantemente cinza, mar- 
rom e preta. Por fim, as aventuras espaciais foram garantidas pelo "Quadrante X", com cenários variando de 174 a 704 peças, coloridas de branco, azul e cinza. Nesse catálogo, as linhas de blocos de encaixe totalizavam 51 brinquedos.

Os lançamentos de blocos de encaixe em 2011 e 2012 seguiram na mesma direção das linhas lançadas em 2010. Ofertados apenas a meninos, esses brinquedos carregavam traços culturalmente construídos como masculinos. Entre cenários de corridas de carros, aventuras espaciais, robôs, meios de transporte variados, obras na cidade, guerras, segurança e defesa de territórios, não foram encontrados vestígios considerados femininos. As cores fortes e variadas aproximavam as brincadeiras da realidade. Mas será que mulheres não transitam por essas realidades? Ou suas imagens são borradas, ficam às sombras?

Buscando ampliar a oferta de brinquedos para meninas e meninos, o catálogo de 2013 passa a ofertar todos os brinquedos para elas e para eles. Cores, temáticas e modelos são mantidos. Mas a indicação de gênero que acompanha cada brinquedo já não direciona o brincar de meninas e meninos. Nesse ano, foi lançada para elas e para eles a linha "Transforça", com 4 brinquedos que poderiam ser transformados em robôs e carros/caminhóes, e variavam de 322 a 593 peças, com cores predominantemente vermelha, preta e amarela, apresentando características semelhantes aos brinquedos antes ofertados apenas para meninos. Contudo, os blocos de encaixe ganhavam, então, outros cenários, outro colorido, com o lançamento do "Reino cor de rosa", para meninas e meninos, em que se ofertava o 'Castelo da Princesa', com 305 peças e cores combinadas entre rosa e roxa. Certamente, com a indicação de todos os brinquedos para meninas e meninos, houve uma preocupação com os estereótipos de gênero que compunham cada peça dos brinquedos ofertados. Se antes os blocos de encaixe eram indicados apenas a meninos, agora, ofertados também a meninas, passaram a contemplar temáticas que reproduziam um padrão de feminilidade.

Em 2014, trazendo a temática de carros, passamos a contar com a "Fórmula Mundi" e suas 303 peças, combinando as cores azul, amarela, verde e vermelha, com detalhes em preto. Para garantir o abastecimento dos veículos, foi inaugurado o "Posto de gasolina", com apenas 67 peças, indicado para crianças a partir de 3 anos de idade, diferente dos demais blocos ofertados até o momento, que apresentavam indicaçáo para maiores de 6 anos de idade. Depois de abastecer, podemos seguir viagem com a "Super Máquina na cidade" (lançamento na linha "Super Máquina", já ofertada), por meio de suas 170 peças, com cores predominantemente vermelha e preta. No caminho, é possível fazer uma parada no "Salão de beleza", composto por 91 peças que combinam as cores rosa, roxa, branca e cinza. Avistamos, enfim, 431 peças nas cores rosa, roxa e cinza, chegando à "Casa de férias".

Os lançamentos de blocos de encaixe com temáticas e cores consideradas femininas, a partir de 2013, quando todos os outros brinquedos passam a ser indicados para eles e para elas, provoca a sensação de uma necessidade de delimitar o feminino e o masculino, mesmo quando esses dois polos já são "permitidos" para meninas e 
meninos. Nesse sentido, a indicaçáo de todos os brinquedos para elas e para eles nos coloca diante de um binarismo camuflado. No entanto, o contexto em que essas modificaçóes ocorrem deve ser levado em consideraçáo. Uma fábrica de brinquedos tem como finalidade, em primeiro lugar, a venda de seus produtos. Desse modo, a oferta de brinquedos, ao mesmo tempo em que interfere na produção cultural, também segue padróes da cultura, ditames de um mercado mundial de brinquedos; portanto, mudanças são apresentadas mas não ocorrem repentinamente.

O catálogo de 2015 traz o exemplo de um grande passo dado em direção a modificaçôes que já se observam nas relações de gênero. Uma nova cozinha é lançada na linha "Casinha Flor", a "Cozinha Top", que apresenta no mesmo brinquedo pia, fogão, forno e lavadora de roupas. Porém, suas cores nada lembram os tradicionais tons de rosa que, até então, coloriam o ambiente doméstico ofertado pela "Casinha Flor". Uma combinação de vermelho, cinza e preto, com detalhes dos botóes em amarelo, configura a nova cozinha, que se mostra mais próxima à realidade e, talvez, mais atraente aos meninos.

A modificação proposta com o lançamento da "Cozinha Top" chamou atenção para a problemática das cores. Por complementarem a imagem do objeto, as cores variam de acordo com os brinquedos ofertados, carregam consigo a intenção de comunicar, condicionando ao brinquedo a produção de determinados sentidos e não outros, em uma dada sociedade. De acordo com Modesto Farina, Clotilde Perez e Dorinhos Bastos (2011, p. 13):

\begin{abstract}
Sobre o indivíduo que recebe a comunicação visual, a cor exerce uma açáo tríplice: a de impressionar, a de expressar e a de construir. A cor é vista: impressiona a retina. E sentida: provoca uma emoção. E é construtiva, pois, tendo um significado próprio, tem valor de símbolo e capacidade, portanto, de construir uma linguagem própria que comunique uma ideia.
\end{abstract}

Partindo dessas consideraçôes, podemos compreender o motivo que levou a Empresa $\mathrm{X}$ a mudar as cores que tingiam o ambiente doméstico. Para se propor unissex, a nova cozinha precisou se despir dos tons de rosa, visto que essa cor é culturalmente associada ao feminino, o que pode ser facilmente observado em inúmeras cenas cotidianas. Roupas, móveis, materiais escolares, decoraçôes, tudo o que se oferta a meninas é marcado pela cor rosa, antes mesmo do bebê nascer. Em contrapartida, para os meninos, todas as cores são bem-vindas, exceto os tons de rosa. Sua masculinidade parece correr perigo quando se aproximam da cor rosa. Mas se não existissem essas imposiçóes culturais, que aprendemos e reproduzimos, será mesmo que a cor preferida de meninas seria rosa? E será mesmo que essa cor seria táo ofensiva aos meninos?

Desse modo, entendemos que a escolha da Empresa X por não utilizar tons de rosa no lançamento da "Cozinha Top" vem comunicar a ideia de uma cozinha unissex, que deixa de se anunciar feminina, mesmo quando já indicada para 
meninas e meninos, visto que essa marca ainda não é convidativa aos meninos, que aprendem, desde muito cedo, a defender uma masculinidade.

Para uma melhor visualização do panorama aqui discutido, no Quadro 1 são apresentadas, ano a ano, as principais características da oferta de brinquedos da Empresa X, nos catálogos de 2009 a 2015.

\section{Quadro 1}

Principais características da oferta de brinquedos da Empresa X, nos catálogos de 2009 a 2015.

\begin{tabular}{|c|c|}
\hline Ano & Principais características da oferta de brinquedos \\
\hline 2009 & $\begin{array}{l}\text { - Oferta do ambiente doméstico às meninas; } \\
\text { - Ambiente doméstico com cores predominantemente rosa e branca; } \\
\text { - Carros de corrida e cenários de guerra ofertados apenas a meninos; } \\
\text { - Direcionamento para o brincar de meninas e meninos. }\end{array}$ \\
\hline 2010 & $\begin{array}{l}\text { - Parte do ambiente doméstico passa a ser ofertada a meninas e meninos, } \\
\text { caracterizando uma divisão sexual do trabalho doméstico; } \\
\text { - O cuidado de bebês ainda é responsabilidade das meninas; } \\
\text { - Com a entrada dos blocos de encaixe nos catálogos, apenas os meninos são } \\
\text { convidados a construir seus brinquedos; } \\
\text { - Corridas de carro, cenários de polícia e bombeiros, obras na cidade e aventuras } \\
\text { espaciais configuram a oferta de brinquedos a meninos, desconsiderando a presença } \\
\text { feminina nesses cenários. }\end{array}$ \\
\hline 2011 & $\begin{array}{l}\text { - É mantida a configuração do catálogo anterior; } \\
\text { - São lançadas duas linhas de blocos de encaixe, trazendo os cenários de aeroporto } \\
\text { e oficina mecânica apenas para meninos, novamente desconsiderando a presença } \\
\text { feminina. }\end{array}$ \\
\hline 2012 & $\begin{array}{l}\text { - É mantida a configuração do catálogo anterior; } \\
\text { - São lançadas quatro linhas de blocos de encaixe, apresentando cenários de } \\
\text { ferroviária, porto, guerra e outras aventuras espaciais, porém as meninas continuam } \\
\text { restritas ao ambiente doméstico. }\end{array}$ \\
\hline 2013 & $\begin{array}{l}\text { - Todos os brinquedos passam a ser ofertados para meninas e meninos; } \\
\text { - São lançados blocos de encaixe com temáticas femininas; } \\
\text { - O feminino e o masculino são possibilitados para elas e para eles, contudo, } \\
\text { conserva-se um binarismo de gênero. }\end{array}$ \\
\hline 2014 & $\begin{array}{l}\text { - É mantida a configuração do catálogo anterior; } \\
\text { - São lançados blocos de encaixe com algumas temáticas tidas como femininas e } \\
\text { outras como masculinas. }\end{array}$ \\
\hline 2015 & $\begin{array}{l}\text { - Parte do ambiente doméstico ganha novas cores, mais atraentes ao público } \\
\text { masculino; } \\
\text { - A presença masculina em cenários domésticos ganha mais visibilidade; } \\
\text { - Os tons de rosa, característicos do feminino, apresentam-se como barreiras que } \\
\text { podem afastar o interesse dos meninos, mais do que os cenários domésticos. }\end{array}$ \\
\hline
\end{tabular}




\section{Considerações finais}

No decorrer desse trajeto, cada catálogo percorrido nos contou um pouco sobre o que vem sendo proposto para o brincar das crianças. Por meio das imagens apresentadas pudemos observar algumas mudanças e permanências em relação às construções de gênero na produção e oferta de brinquedos da Empresa $\mathrm{X}$ nos últimos sete anos. Cada brinquedo ofertado convida crianças a brincar, mas esse convite, muitas vezes, apresenta-se distinto para meninas e meninos.

Após visualizar o panorama dos brinquedos ofertados nesse período, ficou evidente a manutenção de um binarismo de gênero, que delimita o que é masculino e o que é feminino. No período de 2009 a 2012, esse binarismo ficou explícito, direcionando os brinquedos para elas e/ou para eles. Uma construçáo desigual do brincar de meninas e meninos foi anunciada pela oferta de blocos de encaixe apenas para meninos. A eles estava reservada a oportunidade de criar, de construir, de vivenciar as diferentes aventuras sugeridas pelas temáticas desses brinquedos. Em contrapartida, às meninas era possibilitada a reprodução do trabalho doméstico, o cuidado da casa e de bebês.

Contudo, apesar da aparente liberdade de escolhas ofertada a meninos, o que realmente se anuncia é uma privaçáo do brincar, tanto para meninas quanto para meninos, visto que os brinquedos ofertados são igualmente direcionados. Para eles, a vigilância é reforçada; afinal, o feminino foi construído com traços mais leves, delicados, no entanto, muitas vezes é situado como o degrau de apoio para o masculino, que se faz parecer superior, porém à custa de uma inferioridade feminina. Nesse contexto, meninos são privados do cuidado, da sensibilidade, em defesa de uma superioridade negativa, ou seja, que forja sua existência por meio da negação do feminino, mas tendo ele como base, tal qual uma pirâmide, cujo topo só existe em virtude da base que o sustenta.

Em 2010, quando meninos foram convidados a intervir no ambiente doméstico, esse convite se mostrou restrito e configurou uma divisão sexual do trabalho doméstico, mantida até 2012. Para eles foi indicado o auxílio, o trabalho facilitado, não devendo ser os responsáveis pelos afazeres domésticos, tampouco pelo cuidado de bebês, afinal, essas tarefas são culturalmente associadas ao feminino.

As modificaçóes propostas a partir de 2013, quando todos os brinquedos passaram a ser indicados para meninas e meninos, não demonstraram ter se desvinculado de um binarismo. Contudo, essas mudanças já apontaram que transformaçôes vinham ocorrendo nas relaçóes de gênero.

As indicaçôes de gênero que acompanhavam cada brinquedo em catálogo pareciam propor a meninas e meninos a possibilidade de se envolverem nesses dois "universos", construídos como antagônicos, complementares, porém que já se encontravam entrelaçados, com seus limites borrados. Passou a se "permitir" que meninas e meninos se apropriassem de brinquedos "masculinos" e "femininos". 
Mas essa aproximação não é tão simples quanto pode parecer. Será que uma sutil indicação de gênero é capaz de transformar o brincar de meninas e meninos num piscar de olhos? Que outros traços de cultura são inscritos em cada brinquedo ofertado? É preciso levar em consideração que os brinquedos retratam realidades selecionadas, e que essas realidades são marcadas por relaçóes de gênero. Desse modo, cores, ambientes e situações variadas podem nos remeter ao feminino ou masculino. É o que ocorre com os tons de rosa, culturalmente associados ao feminino, que vêm colorindo o ambiente doméstico retratado nos brinquedos.

As cores, que têm muito a nos comunicar, ao complementarem a imagem de um brinquedo, interferem em sua aceitação ou recusa. A aproximação de meninos à cor rosa nem sempre é bem vista. Ao carregarem esse colorido, os brinquedos logo são considerados brinquedos de menina, não importando sua indicação de gênero. Nesse sentido, o lançamento da "Cozinha Top" no catálogo de 2015 renovou o cenário doméstico, despindo-se dos tradicionais tons de rosa. Essa mudança reforçou o convite aos meninos, para que se inserissem ao ambiente doméstico, que já não se apresentava marcado pelo feminino e se propunha unissex.

As relaçóes de gênero passam por transformaçóes, muitas vezes atropeladas por preconceitos. Contudo, essas mudanças nem sempre são retratadas de imediato na produção e oferta de brinquedos. Em uma sociedade capitalista, marcada pelo consumo, uma fábrica de brinquedos deve (re)produzir o que interessa a seu público consumidor. Desse modo, as mudanças observadas na produção e oferta de brinquedos caminham a passos lentos, pois o campo em que se inserem encontra-se minado, é vigiado por normas jamais revisadas.

No entanto, todas essas permanências e modificaçóes apresentadas pelos catálogos no período abordado retratam apenas o que se encontra nos bastidores, ficando a necessidade de investigar a recepção dos brinquedos pelas crianças. Ao entrarem em cena, os brinquedos ganham vida, podem ser transformados pela imaginaçáo das crianças, que não apenas incorporam os sentidos propostos pelos fabricantes, mas criam outros, encenam realidades paralelas, em que nem sempre um roteiro é seguido.

Cada brinquedo aqui abordado carrega consigo muitas sombras, as quais se revelam apenas quando recebem um foco de luz. Muitas sombras podem ser projetadas, todas elas compondo um mesmo objeto. As análises aqui apresentadas não descartam outras interpretaçóes, ao contrário, convidam a novas reflexôes, a partir de outros focos de iluminação.

\section{Notas}

1. A linha "Casinha Flor" é fabricada pela Empresa X e apresenta brinquedos semelhantes aos ofertados pela linha "Disney Princesas", que é uma linha de brinquedos licenciados, a qual não será analisada neste momento. 
2. Conceito abordado por Chodorow (1990) como elemento central e constituinte na organização e reprodução social do gênero. Refere-se ao cuidado; quem materna é aquela pessoa principal, não necessariamente mulher, a cuidar da criança, é quem age de maneira a alimentá-la e ampará-la.

\section{Referências}

ARAÚJO, I. A reconversão do olhar: prática discursiva e produção dos sentidos na intervenção social. São Leopoldo: Ed. da Unisinos, 2000.

ARIÈS, P. História social da criança e da família. Tradução: Dora Flaksman. 2. ed. Rio de Janeiro: Guanabara, 1986.

BENJAMIN, W. Reflexóes sobre a criança, o brinquedo e a educação. São Paulo: Editora 34, 2002.

BOMTEMPO, E. A brincadeira de faz de conta: lugar do simbolismo, da representação, do imaginário. In: KISHIMOTO, T.M. (Org.). Jogo, brinquedo, brincadeira e a educaçâo. 14. ed. São Paulo: Cortez, 2011.

BROUGÈRE, G. Brinquedo e cultura. Revisão técnica e versão brasileira adaptada por Gisela Wajskop. 8. ed. São Paulo: Cortez, 2010. (Coleção Questóes da Nossa Época, 20).

BRUSCHINI, M.C.A. Trabalho e gênero no Brasil nos últimos dez anos. Cadernos de Pesquisa, v. 37, n. 132, p. 537-572, set./dez. 2007.

CERTEAU, M. de. A invenção do cotidiano: artes de fazer. 3. ed. Petrópolis: Vozes, 1998.

CHODOROW, N. Psicanálise da maternidade: uma crítica a Freud a partir da mulher. Tradução: Nathanael C. Caixeiro. Rio de Janeiro: Rosa dos Tempos, 1990.

COHN, C. Antropologia da criança. Rio de Janeiro: Jorge Zahar, 2005.

FARINA, M.; PEREZ, C.; BASTOS, D. Psicodinâmica das cores em comunicação. 6. ed. São Paulo: Blucher, 2011.

HIRATA, H.; KERGOAT, D. Novas configuraçôes da divisão sexual do trabalho. Cadernos de Pesquisa, v. 37, n. 132, p. 595-609, set./dez. 2007.

KERGOAT, D. Divisão sexual do trabalho e relaçóes sociais de sexo. In: EMÍLIO, M. et al. (Orgs.). Trabalho e cidadania ativa para as mulheres: desafios para as políticas públicas. São Paulo: Coordenadoria Especial da Mulher, 2003. p. 55-63.

KISHIMOTO, T.M. O jogo e a educação infantil. In: KISHIMOTO, T.M. (Org.). Jogo, brinquedo, brincadeira e a educação. 14. ed. São Paulo: Cortez, 2011.

OLIVEIRA, P.S. O que é brinquedo? 2. ed. São Paulo: Brasiliense, 1989. (Coleção Primeiros Passos, 138).

PENN, G. Análise semiótica de imagens paradas. In: BAUER, M.W.; GASKELL, G. (Eds.). Pesquisa qualitativa com texto, imagem e som: um manual prático. Tradução: Pedrinho A. Guareschi. 2. ed. Petrópolis: Vozes, 2002. p. 319-342.

ROCHA, M.S.P.M.L. Não brinco mais: a (des)construção do brincar no cotidiano educacional. 2. ed. Ijuí: Ed. Unijuí, 2005. (Coleção Fronteiras da Educação). 
SAFFIOTI, H.I.B. Rearticulando gênero e classe social. In: COSTA, A.O.; BRUSCHINI, C. Uma questão de gênero. Rio de Janeiro: Rosa dos Tempos; São Paulo: Fundação Carlos Chagas, 1992.

STAVISKI, G.; KUNZ, E. Sem tempo de ser criança: o se-movimentar como possibilidade de transgredir uma insensibilidade para o momento presente. In: KUNZ, E. (Org.). Brincar e se-movimentar: tempos e espaços de vida da criança. Ijuí: Unijuí, 2015. 136 p. (Coleção Educação Física).

VIANNA, C.; FINCO, D. Meninas e meninos na educação infantil: uma questão de gênero e poder. Cadernos Pagu, São Paulo, n. 33, p. 265-283, jul./dez. 2009.

WINNICOTT, D.W. O brincar e a realidade. Rio de Janeiro: Imago, 1975. (Coleção Psicologia Psicanalítica).

Recebido em 17 de outubro de 2015.

Aprovado em 7 de fevereiro de 2016. 